\title{
Discourse Theory and Political Analysis: Identities, Hegemonies and Social Change
}

D. Howarth, A. J. Norval and Y. Stavrakakis (eds.)

Manchester University Press, Manchester, 2000, 254pp.

ISBN: 0 7190-5663-2 hb., 0 7190-5664-0 pb.

This excellent collection should finally lay to rest the idea that discourse theory is without practical application. It is chock-a-block with insight into areas as diverse as Argentine politics after Peronist populism, new environmental movements and the campaign against Manchester Airport's second runway, Romanian social democracy, women's struggles in Chiapas and Turkish politics between 1960 and 1990 (to mention a few). Seeing all the tools of discourse theory brought to bear on such a wide range of case-studies there can be little doubt that the results are every bit as persuasive, rigorous, methodologically sound and theoretically sensitive as those offered by the other contenders for the title of 'approach best suited to the study of political phenomena' such as rational choice theory, institutional analysis and normative political philosophy. Where scepticism about the utility of discourse theory remains, where haughty disdain still greets this player on the methodological scene, it will surely be as a result of not having read this book.

Of course, one of the reasons that discourse theory has struggled to gain recognition amongst more mainstream forms of political analysis is the perceived and, in some cases, actual tendency for discourse theorists to cloud their insights with both terminological proliferation for its own sake and argumentative strategies which rely more on paradox and contradiction than on clarity and consistency. Of course, all forms of political inquiry are prone to these problems but it did appear that discourse theory was, at times, particularly unwilling to gaze beyond the confines of its own navel. The opening essay by Howarth and Stavrakakis conclusively demonstrates that the tendency towards obfuscation within discourse theory is not an intrinsic aspect of its methodological focus. Indeed, their account of the key assumptions motivating discourse theory, its emergence within a competitive methodological terrain and the definitions they put forward of basic terms within discourse theory exemplifies the kind of analytical sharpness that is so often sadly lacking in the writings of political analysts from more traditional methodological backgrounds. Lack of definition, conceptual vagueness and methodological uncertainty are no longer plausible excuses for ignoring the insights of discourse theory or for refusing to consider discourse analysis in the construction of research programmes. 
While these gains are to the credit of the editors it is important to recall that the editors themselves are part of a larger project that began with the establishment of the 'Ideology and Discourse Analysis' programme at the University of Essex in 1982, a programme from which all the contributors have graduated at various times since. Of course, the intellectual high water mark of discourse analysis came with the publication of Laclau and Mouffe's Hegemony and Socialist Strategy (1985). This classic of post-Marxism provides the conceptual frame for all of the contributions and it is the benchmark against which all the contributors measure the success of their work. This should not, though, be taken to suggest that this collection is an exercise in simply reiterating the arguments of Laclau and Mouffe. As Norval's concluding essay makes clear, there is much that needs to be refined in Laclau and Mouffe's classic and in their work since (most of which has not been collaborative). Such amendments to the basic theory, however, contribute to the internal strength of discourse theory and testify to its vitality while other methodological approaches look rather dormant or decaying. All of which provides ample evidence to support the kind of collective endeavours that have marked research into discourse theory at Essex over the last 20 years.

\section{References}

Laclau, E. Mouffe, C. (1985) Hegemony and Socialist Strategy. London: Verso.

Iain MacKenzie The School of Politics, Queen's University, Belfast. 